NASA Technical Memorandum 106712

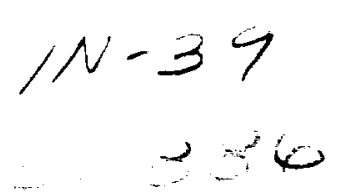

NASA Techical Memorandum 106712

$p, 19$

\title{
Probabilistic Simulation of Stress Concentration in Composite Laminates
}

C.C. Chamis and P.L.N. Murthy

National Aeronautics and Space Administration

Lewis Research Center

Cleveland, Ohio

D.G. Liaw

Sverdrup Technology, Inc.

Lewis Research Center Group

Brook Park, Ohio

Prepared for the

34th Structures, Structural Dynamics, and Materials (SDM) Conference cosponsored by AIAA, ASME, ASCE, AHS, and ASC

La Jolla, California, April 19-22, 1993

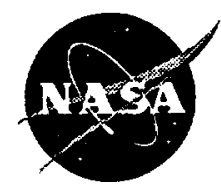

National Aeronautics and Space Administration
(NASA-TM-106712) PROBABILISTIC

SIMULATIUN OF STRESS CONCENTRATION

IN COMPOSITE LAMINATES

Lewis Research center)

(NASA.

$19 P$
N95-17270

Unclas 



\title{
PROBABILISTIC SIMULATION OF STRESS CONCENTRATION IN COMPOSITE LAMINATES
}

\author{
C.C. Chamis and P.L.N. Murthy \\ NASA Lewis Research Center \\ Cleveland, Ohio 44135 \\ and \\ D.G. Liaw \\ Sverdrup Technology, Inc. \\ Lewis Research Center Group \\ Brook Park, Ohio 44142
}

\section{SUMMARY}

A computational methodology is described to probabilistically simulate the stress concentration factors (SCF's) in composite laminates. This new approach consists of coupling probabilistic composite mechanics with probabilistic finite element structural analysis. The composite mechanics is used to probabilistically describe all the uncertainties inherent in composite material properties, whereas the finite element is used to probabilistically describe the uncertainties associated with methods to experimentally evaluate SCF's, such as loads, geometry, and supports. The effectiveness of the methodology is demonstrated by using it to simulate the SCF's in three different composite laminates. Simulated results match experimental data for probability density and for cumulative distribution functions. The sensitivity factors indicate that the SCF's are influenced by local stiffness variables, by load eccentricities, and by initial stress fields.

\section{INTRODUCTION}

It is generally accepted that flawed structures (those with holes or cracks) fail because stress concentrations cause damage of such magnitude that (1) the structure cannot safely perform as designed and qualified or (2) catastrophic global fracture is imminent. According to the authors' knowledge, this is true for structures made from traditional homogeneous materials as well as for fiber composites. The difference between fiber composites and traditional materials is that composites have multiple fracture modes that initiate local flaws whereas traditional materials have only a few. Stress concentrations in composites are influenced by uncertainties in many more factors than in metals because of the inherent anisotropic and layered structure of composites. Any predictive approach for simulating stress concentrations in fiber composites needs to formally quantify (1) all possible fracture modes, (2) the types of flaws they initiate, and (3) the uncertainties that influence the magnitude of the stress concentration.

One of the ongoing research activities at the NASA Lewis Research Center is the development of a methodology for "probabilistic structural analysis" in general. A part of this methodology consists of step-by-step procedures to probabilistically quantify the uncertainties in composite behavior such as ply and laminate mechanical, thermal, and heat transfer properties (refs. 1 and 2) and composite structural response such as displacement, stress, and vibration frequency (ref. 3). The methodology has been embedded in the computer code IPACS (Integrated Probabilistic Assessment of Composite Structures, ref. 4) through the integration of two NASA Lewis in-house codes: PICAN (Probabilistic Integrated Composite ANalyzer, ref. 5) and NESSUS (Numerical Evaluation of Stochastic Structures under Stress, ref. 6). Another new application of that approach is to probabilistically simulate the range 
of scatter (uncertainties) in stress concentration factors (SCF's) in composite laminates. This simulation provides a formal method to (1) assess alternative designs with respect to their reliability and/or (2) to quantify the probability that the magnitude of the SCF's would be within an acceptable range. This report describes the fundamental aspects of this approach and illustrates its application by probabilistically simulating SCF's in several composite laminates and discussing their significance.

\section{SYMBOLS}

$\begin{array}{ll}e & \text { eccentricity } \\ M & \text { moisture } \\ P & \text { pressure } \\ T & \text { use temperature } \\ t & \text { time } \\ X_{i} & \text { design parameter } \\ \sigma & \text { stress } \\ \sigma_{A} & \text { applied stress } \\ \sigma_{C} & \text { stress in composite } \\ \sigma_{x} & \text { axial stress } \\ \sigma_{x y} & \text { shear stress } \\ \sigma_{y} & \text { transverse stress }\end{array}$

\section{FUNDAMENTAL CONCEPTS}

\section{Computational Simulation}

A brief description of the fundamental concepts for the computational methodology is included for completeness. Uncertainties (scatter) in composite laminates and composite structures result from their inherent nature and from their fabrication process (fig. 1). The SCF's in composite laminates are probabilistically assessed by using the IPACS code (ref. 4). This code integrates the probabilistic composite mechanics in PICAN (ref. 5) with the probabilistic finite element structural analysis in NESSUS (ref. 6). A schematic of this integrated computer code is shown in figure 2.

Probabilistic composite mechanics is used to formally describe all the uncertainties associated with the composite-from micromechanics to laminate. The uncertainties are incorporated in the primitive variables that describe the laminate in the composite mechanics equations. These include constituent material properties, fabrication process variables, ply orientation angles, and ply thickness (refs. 1 and 2). These uncertainties are accounted for in PICAN (fig. 2). Typical values for boron, glass, graphite, and epoxy materials are listed in table I.

Probabilistic structural analysis is used to formally describe the uncertainties associated with the structure. The uncertainties are incorporated in the primitive variables in the structural mechanics equations that define the structure. They include special geometry, boundary conditions, and load conditions (ref. 3). These uncertainties are accounted for by NESSUS (fig. 2).

The simulation process in IPACS is as follows:

(1) The scatter in all the primitive variables that describe the composite can be represented by well-known probabilistic distributions.

(2) The values for the primitive variables can be randomly selected from the known distributions for a specific composite. 
(3) These values can be used in composite mechanics to predict composite behavior.

(4) The whole process can be repeated many times to obtain sufficient information to develop the distribution of the ply properties, composite properties, or structural responses.

These concepts are analogous to making and testing composites. The probabilistic distributions represent uncertainties of available materials that the composite can be made from. The composite mechanics represents the physical experiment, and the process repetition represents several experiments. Subsequent statistical analysis of the data is the same for both approaches. The primitive variables that describe the composite are identified by examining the fabrication process, the structural assembly, the boundary conditions, and the loading conditions. During the simulation process, sensitivity factors are also evaluated. The sensitivity factors rank all the participating random variables according to the probable significance of a specific structural response. The commonly used sensitivity in a deterministic analysis is the performance sensitivity $\partial Z / \partial X_{i}$, which measures the change in the performance $Z$ due to the change in a design parameter $X_{i}$. This concept is extended to the probabilistic simulation to define the probabilistic sensitivity, which measures the change in the probability or reliability relative to the change in each random variable, including both physical significance and scatter of that random (primitive) variable.

\section{Closed-Form Equation}

Another fundamental concept includes the closed-form equations (CFE's) for concentration factors (ref. 7). The equations are based on circular holes in infinite laminates. The equations for the SCF's are included in PICAN, which can be used to evaluate them probabilistically. Then, the results can be compared with those obtained from IPACS.

\section{RESULTS AND DISCUSSION-LAMINATE STRESS CONCENTRATION FACTORS}

SCF's for three different laminate composite systems (boron/epoxy, E-glass/epoxy, and graphite/epoxy, respectively) were evaluated. The finite element model used, the various uncertainties considered (including combined stresses, results obtained, and their significance to laminate integrity), and comparisons with the CFE and with available data are discussed in this section.

\section{Laminate Finite Element Model}

The laminates were 20 by 10 in. with a center hole of 1 in. diameter and a thickness of 10 plies, or about 0.05 in. They were loaded (1) in tension parallel to the 20 -in. dimension and (2) under combined stresses to evaluate these effects on the SCF. Figure 3 shows the finite element model of the laminates. The laminate configuration, $[0 / \pm 45 / 0 /]_{\mathrm{s}}$, was the same for all three composite systems.

\section{Boron Epoxy Laminate}

Figure 4 shows the scatter in the SCF in terms of the probability density function (PDF), or frequency of occurrence. The range of uncertainties included in the IPACS simulation are summarized in the figure for the reader's convenience. Three different distributions are shown in this figure: (1) simulated by IPACS, (2) independent source (the Monte Carlo simulation), and (3) experimental data. The independent source distribution and the experimental data are from reference 8 . The PDF 
and the cumulative distribution function (CDF) for the experimental data were generated by the authors from the range and mean value of the experimental data given in reference 8. IPACS simulates the experimental data almost exactly, whereas the independent source overpredicts the mean and the range. Figure 4 also shows the corresponding CDF (probability of occurrence). Again, the IPACS and experimental data are identical for all practical purposes.

In addition, figure 4 shows the sensitivity factors for two levels of probability. It is interesting to note that of about 40 primitive variables used, only 4 have a significant effect on the SCF. All four of these primitive variables define local stiffness, demonstrating that SCF's are predominantly stiffness controlled. Comparisons of the IPACS' simulated range of uncertainty in the SCF with that predicted by using the CFE (ref. 7) are shown in figure 5 for two ranges of uncertainties in the primitive variables. Note that the experimental data range is shown by the cross-hatched bar. The following observations are worth noting:

(1) The CFE overpredicts the mean of the stress concentration by about 20 percent.

(2) The CFE predicts a smaller range for both the 2 and 5 percent uncertainties than the IPACS simulations do.

(3) The CFE does not agree with the experimental data.

(4) A 5-percent uncertainty in the primitive variables increases the uncertainty range by almost 4 times in the IPACS simulation but only by 2 times in the CFE.

An important conclusion is that the whole laminate must be modeled in order to adequately represent the uncertainty range in the SCF. It is very important to keep in mind that the uncertainty ranges simulated by the SCF's must be compared with the laminate's respective local strength in order to assess this laminate's resistance to fracture initiation for a specific applied stress magnitude.

\section{Glass Epoxy Laminate}

Figure 6 shows the uncertainty range of the SCF in glass/epoxy laminates. Note that a 3-percent uncertainty of the laminate thickness out-of-plane eccentricity was included in this laminate. The reason for this eccentricity is that the IPACS simulation predicted the shape of the PDF but not the mean of the experimental data (ref. 8). The mean without the eccentricity was about 3.2 compared with a mean of about 3.5 for the experimental data. Other uncertainties such as in-plane eccentricities and greater range in ply misorientation had negligible influence on the mean. Hindsight shows that probable eccentricity should have been included in the initial simulation. An important observation is that IPACS captures the uncertainty range of the SCF provided that all probable uncertainties are included. As a side note, the same amount of eccentricity had a negligible effect on the SCF for the boron/epoxy laminate.

Figure 6 also shows the corresponding CDF for the glass/epoxy laminate. For all practical purposes, the IPACS simulation reproduces the experimental data.

The sensitivity factors are summarized in the bar chart in figure 6 . Note that the sensitivity factor for the out-of-plane eccentricity is of about the same order as that for the ply thickness. The eccentricity is fourth in significance after the longitudinal fiber modulus, the fiber volume ratio, and the ply misorientation range. Uncertainties in the remaining primitive variables for the glass, fiber, matrix and the fabrication variables (table I) have a negligible effect.

An important conclusion from the collective results shown in figure 6 is that the probable uncertainties in all participating primitive variables need to be included in the probabilistic simulation of a specific laminate property or response. It is generally prudent to do so because the sensitivity factors will rank the significance of each primitive variable and the dominant ones will be identified. These dominant variables can then be used in subsequent detailed analysis as required. 


\section{Graphite Epoxy Laminate}

Figure 7 shows the uncertainty range in the SCF of graphite/epoxy laminates in comparison to experimental data and predictions from an independent source (ref. 8). As for the glass-epoxy laminates, a 7-percent out-of-plane eccentricity of the laminate thickness was used to shift the IPACSsimulated PDF to the right to match the experimental data. Otherwise, the shape of the PDF was identical.

Figure 7 also shows the corresponding CDF's. They are coincident as would be expected from the very good agreement of the PDF's. The respective sensitivity factors are shown in the bar chart in this figure. The three dominant primitive variables are those that control local stiffness-fiber modulus, fiber volume ratio, and ply misorientation. The eccentricity is the fourth dominant primitive variable with a magnitude of about one-half of the fiber modulus. Two obvious questions surface at this point for both the glass/epoxy and the graphite/epoxy laminates:

(1) If the eccentricity is not dominating (does not have a high sensitivity factor), why should it be even included?

(2) Why not increase the range in the dominating variables?

The answers follow:

(1) The sensitivity factors of the dominant primitive variables include both physical and probabilistic effects.

(2) Increasing the range of the dominating primitive variables spreads the uncertainty range of the SCF but does not shift the mean.

These answers are important and lead to the following general observation: When the shapes of the IPACS-simulated probabilistic distributions are identical, or nearly so, with those of the measured data but are separated by some amount, then either (1) the in situ mean of one of the primitive variables is off (by an amount equal to the difference between the two means) or (2) a primitive variable is missing in the probabilistic simulation. This can be generally resolved by examining the specific case and may require additional simulations (such as a finer mesh near the hold if the probabilistically simulated mean is less than that of the data). The feedback from the results will indicate which is correct.

\section{Uncertainties of Initial Thermal Stress Fields}

It is well known that because of their fabrication process composite laminates have initial thermal stress fields that require cooling down from cure temperatures to room temperature during curing. It is reasonable to assume that this temperature will not be uniform and will cause nonuniformities in the residual stresses. These nonuniformities, in turn, may cause eccentricities and affect the laminate SCF. Although these stress nonuniformities are not known, they can be represented as uncertainties and quantified by using IPACS to simulate their effects on the SCF.

The effects on initial stresses due to a temperature through-the-thickness gradient of $80^{\circ} \mathrm{F}$ with a $\pm 5^{\circ} \mathrm{F}$ scatter on the SCF in glass/epoxy laminates are shown in figure 8 . All the other uncertainties were identical except the uncertainty for the out-of-plane eccentricity. As can be seen, IPACS simulates the uncertainty range in the SCF without requiring out-of-plane eccentricity. This is significant indeed because the uncertainties due to initial thermal stresses are more likely to be unsuspected than those caused by load eccentricities. Comparing the sensitivity factors to those in figure 6 shows that the dominance of the fiber modulus increased from 0.6 to 0.7 , whereas the dominance of the fiber volume ratio decreased from 0.6 to 0.5 . The temperature replaced the dominance of the eccentricity with approximately the same magnitude. This observation implies that the thermal stress effect causes laminate out-of-plane displacements comparable to those induced by eccentricities. 
Corresponding initial stress uncertainties in the SCF of graphite epoxy laminates are shown in figure 9. An important observation is that the initial stress uncertainties are not sufficient to eliminate the out-of-plane eccentricity for this laminate. However, these uncertainties reduced the eccentricity's significance from 7 percent to 3.5 percent, or by one-half. The sensitivity factors show that the temperature uncertainty is of about the same magnitude as the out-of-plane eccentricity uncertainty. As for the glass/epoxy laminates, the modulus sensitivity increased in significance, whereas the fiber volume ratio sensitivity decreased. Another important conclusion is that temperature is another primitive variable which introduces uncertainties that must be included in the IPACS simulation.

\section{Uncertainties of Combined Stresses}

The combined stresses that may result from the test fixture are another source of probable uncertainties. These effects are shown in figure 10 for the graphite/epoxy laminate. Some important observations are that the uncertainties of $\sigma_{y}$ and $\sigma_{x y}$ stresses have no influence on the range of uncertainties in the SCF; however, the uncertainty of the $\sigma_{x}$ stress changes the SCF's shape.

The corresponding sensitivity factors are also shown in figure 10. The sensitivity factor for the $\sigma_{x}$ stress dominates and even exceeds that for the fiber modulus, which was previously the dominant primitive variable for the SCF. Also, the sensitivity factor for the $\sigma_{y}$ stress is greater than those for the ply thickness and eccentricity. However, the residual stress due to cure temperature did not even appear in the ranking. One conclusion is that the residual stress affects only ply stresses that are internal to the laminate and that cannot be evaluated from laminate tests. Another observation is that the applied stress field effect, depending on its magnitude, may override the effect of any eccentricities from residual stresses. Back-to-back strain gauges will distinguish this effect in the experimental evaluations especially under low levels of load.

\section{GENERAL COMMENTS}

From the previous observations and discussion, the following general comments are worthy of note for the probabilistic assessment of SCF.

(1) Probabilistic evaluation provides a priori information for preparing a test plan and estimating the range of measured values of the SCF if the laminate was (a) fabricated as designed and (b) tested according to the test plan.

(2) Sensitivity factors offer a direct means to identify which primitive variables dominate, which variables are insignificant, and which may have been missed in the simulation. They also provide guidelines to improve designs and may indicate what went wrong during testing.

(3) Probabilistic evaluation provides guidelines for (a) the minimum number of experiments and (b) quality criteria for material acceptance and for fabrication tolerances to assure that specific designs will meet reliability and safety requirements.

(4) Probabilistic evaluations combined with probabilistic strengths will provide quantifiable information to assess risk for a specified reliability.

Collectively, these points provide designers and manufacturers with metrics to make judicious decisions that result in reliable products with specified life-cycle costs.

\section{SUMMARY OF RESULTS}

The stress concentration factor (SCF) in composite laminates was probabilistically evaluated

for three different composite systems (boron, glass, and graphite fiber (epoxy). The SCF's were 
simulated computionally with the computer code IPACS (Integrated Probabilistic Assessment of Composite Structures), which consists of probabilistic composite mechanics and probabilistic finite element structural analysis. The following results were obtained:

1. The SCF means and scatter ranges predicted by IPACS are in very good agreement with available data for the three laminates.

2. The sensitivity factors indicate that the primitive variables for local stiffness (fiber, modulus, fiber volume ratio, and ply misorientation) have the greatest influence on the probable magnitude of SCF's.

3. A 7-percent out-of-plane eccentricity in the load application increased the mean by about 22 percent of the SCF in graphite/epoxy laminates. Back-to-back strain gages must be used to measure SCF's in composite laminates.

4. Nonuniformities in initial stress fields (for example, unsymmetric residual stress induced by curing) cause laminate bending. The effects of these nonuniformities on SCF's are similar to those of out-of-plane load eccentricities.

\section{REFERENCES}

1. Stock, T.A., et al.: Probabilistic Approach to Composite Micromechanics. NASA TM-101366, 1988.

2. Mase, G.T.; Murthy, P.L.N.; and Chamis, C.C.: Probabilistic Micro and Macromechanics of Polymer Matrix Composites. NASA TM-103669, 1990.

3. Chamis, C.C.: Probabilistic Structural Analysis Methods for Space Propulsion System Components. NASA TM-88965, 1986.

4. Shiao, M.C.; Singhal, S.N.; Chamis, C.C.: A Method for the Probabilistic Design Assessment of Composite Structures. NASA TM-106384, 1992.

5. Liaw, D.G.; Shiao, M.C.; Singhal, S.N.; and Chamis, C.C.: Probabilistic Simulation of Multi-Scale Composite Behavior. NASA TM-106196, 1993.

6. Probabilistic Structural Analysis Methods (PSAM) for Select Space Propulsion System Components Users Manual. Southwest Research Institute, NASA Contract NAS3-29389, Nov. 1989.

7. Chamis, C.C.; and Ginty, C.A: Fiber Composite Structural Durability and Damage Tolerance: Simplified Predictive Methods. NASA TM-100179, 1987.

8. Lenoe, E.M.; Neal, D.M.: Effects of Variability of Design Parameters on Stress Concentration Estimates. Proceedings: Composite Materials-The Influence of Mechanics of Failure on Design. Army Symposium on Solid Mechanics, Cape Cod Massachusetts, Sept. 14-16, 1976, pp. 171-191. 
TABLE L-PRIMTTIVE VARIABLES AND ASSOCIATED UNCERTAINTIES

(a) Fibers.

\begin{tabular}{|c|c|c|c|c|c|}
\hline \multirow[t]{3}{*}{ Primitive variable } & \multirow[t]{3}{*}{ Units } & \multirow{3}{*}{$\begin{array}{l}\text { Distribution } \\
\text { type }\end{array}$} & \multicolumn{3}{|c|}{ Mean value } \\
\hline & & & \multicolumn{3}{|c|}{ Fiber } \\
\hline & & & Boron ${ }^{a}$ & Glass $^{b}$ & Graphite $^{b}$ \\
\hline $\begin{array}{l}\text { Modulus } \\
\text { In longitudinal direction } \\
\text { In transverse direction } \\
\text { Shear modulus } \\
\text { In plane } \\
\text { Out of plane } \\
\text { Poisson's ratio } \\
\text { In plane } \\
\text { Out of plane } \\
\text { Thermal expansion coefficien } \\
\text { In longitudinal direction } \\
\text { In transverse direction } \\
\text { Density } \\
\text { Number of fibers per end } \\
\text { Diameter } \\
\text { Heat capacity } \\
\text { Heat conductivity } \\
\text { In longitudinal direction } \\
\text { In transverse direction } \\
\text { In out-of-plane direction } \\
\text { Strength } \\
\text { Tensile } \\
\text { Compressive }\end{array}$ & 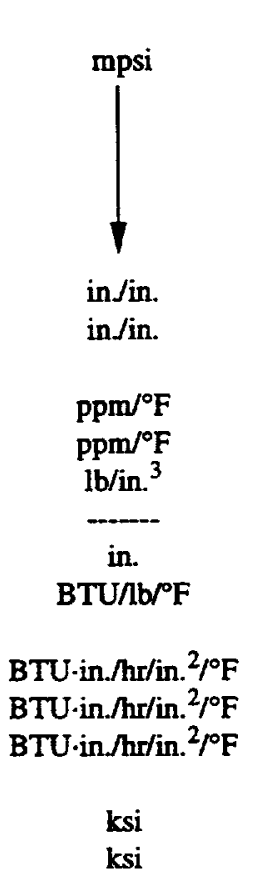 & $\begin{array}{c}\downarrow \\
\text { Fixed } \\
\text { Normal }\end{array}$ & $\begin{array}{c}58.0 \\
58.0 \\
\\
24.2 \\
24.2 \\
\\
0.2 \\
0.2 \\
\\
2.8 \\
2.8 \\
.095 \\
1 \\
.004 \\
.31 \\
\\
1.55 \\
1.55 \\
1.55 \\
\\
600 \\
700\end{array}$ & $\begin{array}{c}12.4 \\
12.4 \\
\\
5.17 \\
5.17 \\
.2 \\
.2 \\
2.8 \\
2.8 \\
.09 \\
204 \\
.00036 \\
.17 \\
.625 \\
.625 \\
.625 \\
\\
360 \\
60\end{array}$ & $\begin{array}{c}38.0 \\
1.1 \\
\\
1.5 \\
.8 \\
\\
.2 \\
.25 \\
\\
-.55 \\
5.6 \\
.063 \\
10000 \\
.0003 \\
.17 \\
\\
4.03 \\
.403 \\
.403 \\
\\
350 \\
250\end{array}$ \\
\hline
\end{tabular}

(b) Matrix and fabrication variables.

\begin{tabular}{|c|c|c|c|}
\hline Primitive variable & Units & $\begin{array}{c}\text { Distribution } \\
\text { type }\end{array}$ & Mean value \\
\hline \multicolumn{4}{|c|}{ Matrix ${ }^{a}$} \\
\hline $\begin{array}{l}\text { Modulus } \\
\text { Shear modulus } \\
\text { Poisson's ratio } \\
\text { Thermal expansion coefficient } \\
\text { Density } \\
\text { Heat capacity } \\
\text { Heat conductivity } \\
\text { Tensile strength } \\
\text { Compressive strength } \\
\text { Shear strength } \\
\text { Moisture coefficient } \\
\text { Diffusivity }\end{array}$ & $\begin{array}{c}\text { mpsi } \\
\text { mpsi } \\
\text { in } / \text { in. } \\
\mathrm{ppm} /{ }^{\circ} \mathrm{F} \\
\text { bb/in. }{ }^{3} \\
\text { BTU/hb/ }{ }^{\circ} \mathrm{F} \\
\mathrm{BTU} \cdot \mathrm{in} / \mathrm{hr} /{ }^{2}{ }^{2}{ }^{\circ} \mathrm{F} \\
\mathrm{ksi} \\
\text { ksi } \\
\text { ksi } \\
\text { in } / \text { in } / 1 \text {-percent } \\
\text { moisture }\end{array}$ & $\begin{array}{l}\text { Weibull } \\
\text { Weibull } \\
\text { Weibull } \\
\text { Normal } \\
\text { Normal }\end{array}$ & $\begin{array}{l}0.5 \\
.185 \\
.35 \\
42.8 \\
.0443 \\
.25 \\
.104 \\
15.0 \\
35.0 \\
13.0 \\
.004 \\
.0002\end{array}$ \\
\hline \multicolumn{4}{|c|}{ Fabrication variables } \\
\hline $\begin{array}{l}\text { Fiber volume ratio } \\
\text { Void volume ratio } \\
\text { Ply thickness } \\
\text { Ply misalignment }\end{array}$ & $\begin{array}{l}\text { percent } \\
\text { percent } \\
\text { in. } \\
\text { in. }\end{array}$ & $\left.\right|_{1} ^{\text {Normal }}$ & $\begin{array}{l}{ }^{250} \\
{ }^{2} 0.0 \\
a^{2} .0055 \\
c_{0}\end{array}$ \\
\hline
\end{tabular}




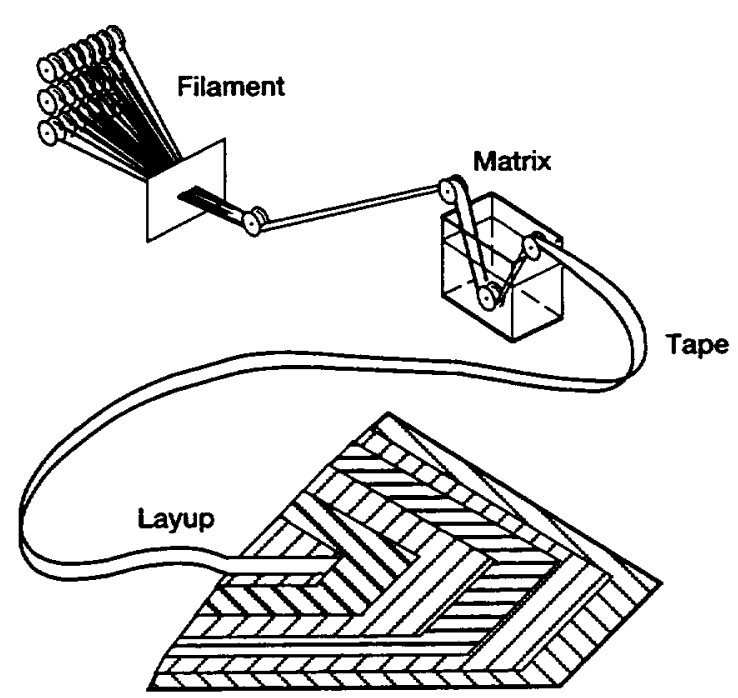

Fabrication schematic

- Constituents

(Fiber and matrix properties)

- Fiber misalignment

- Fiber volume ratio

- Void volume ratio

- Ply misalignment

- Ply thickness

Figure 1.-Random variables in the typical fabrication process.

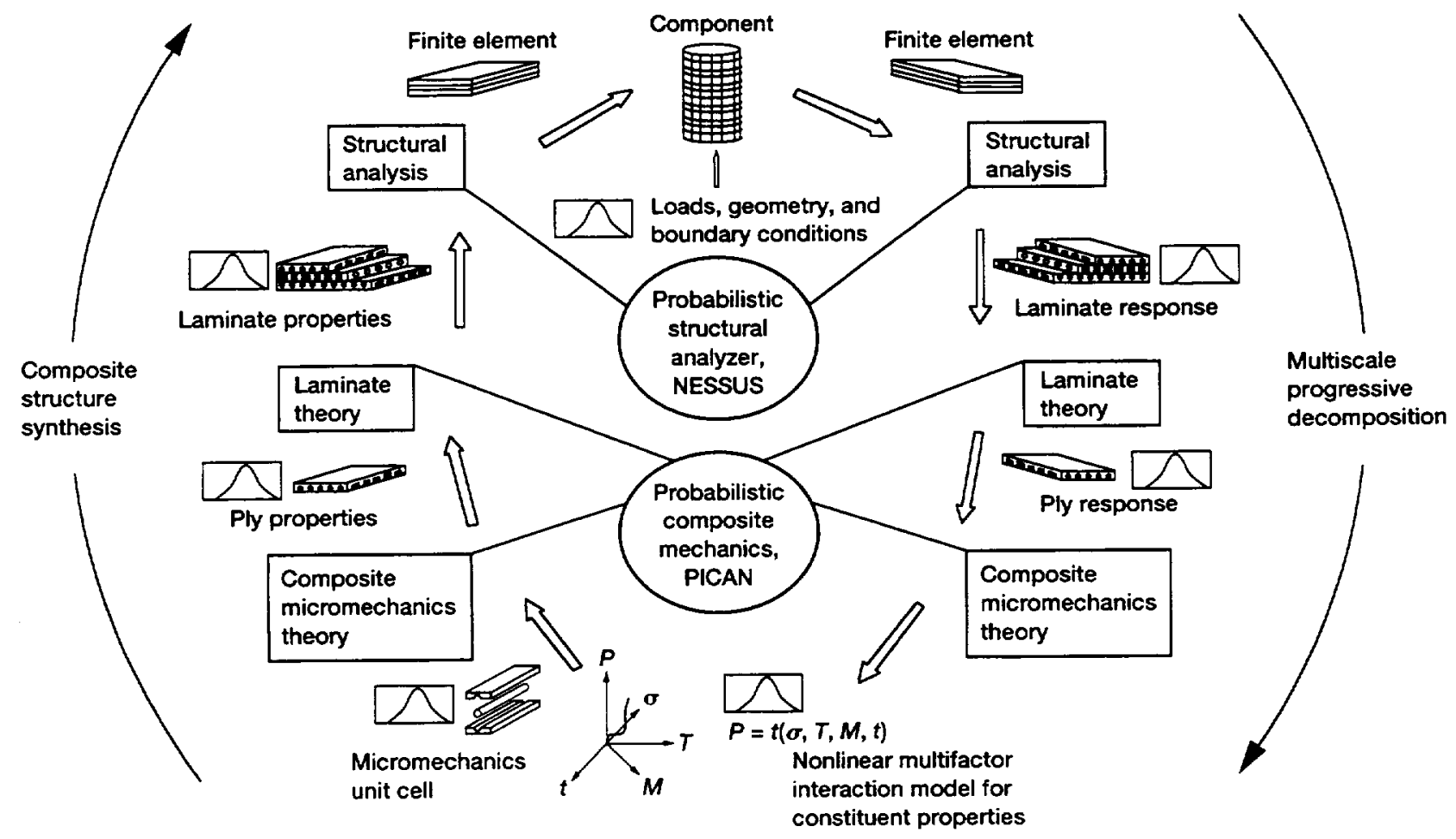

Figure 2.-Integrated probabilistic assessment of composite structures (IPACS). 


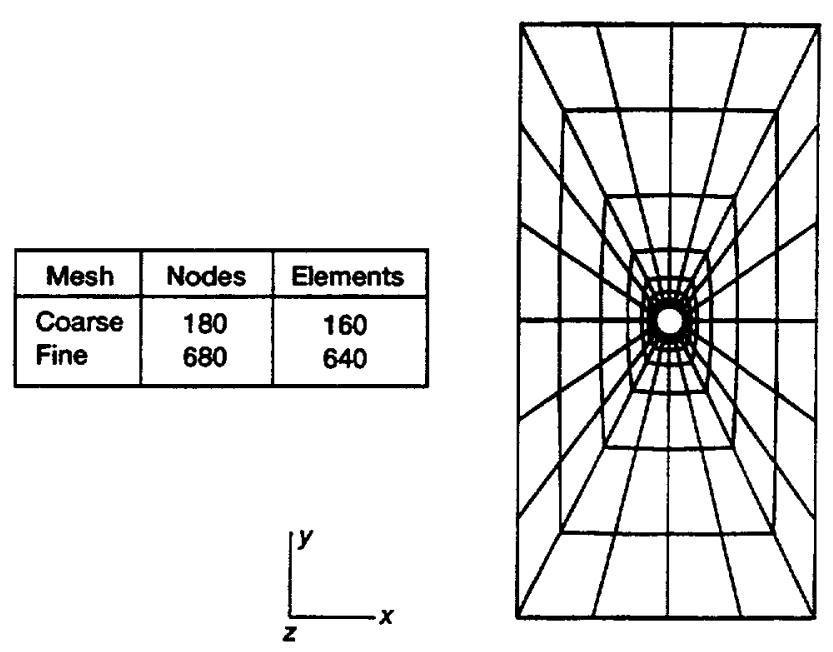

Figure 3.-Finite element modeling. 

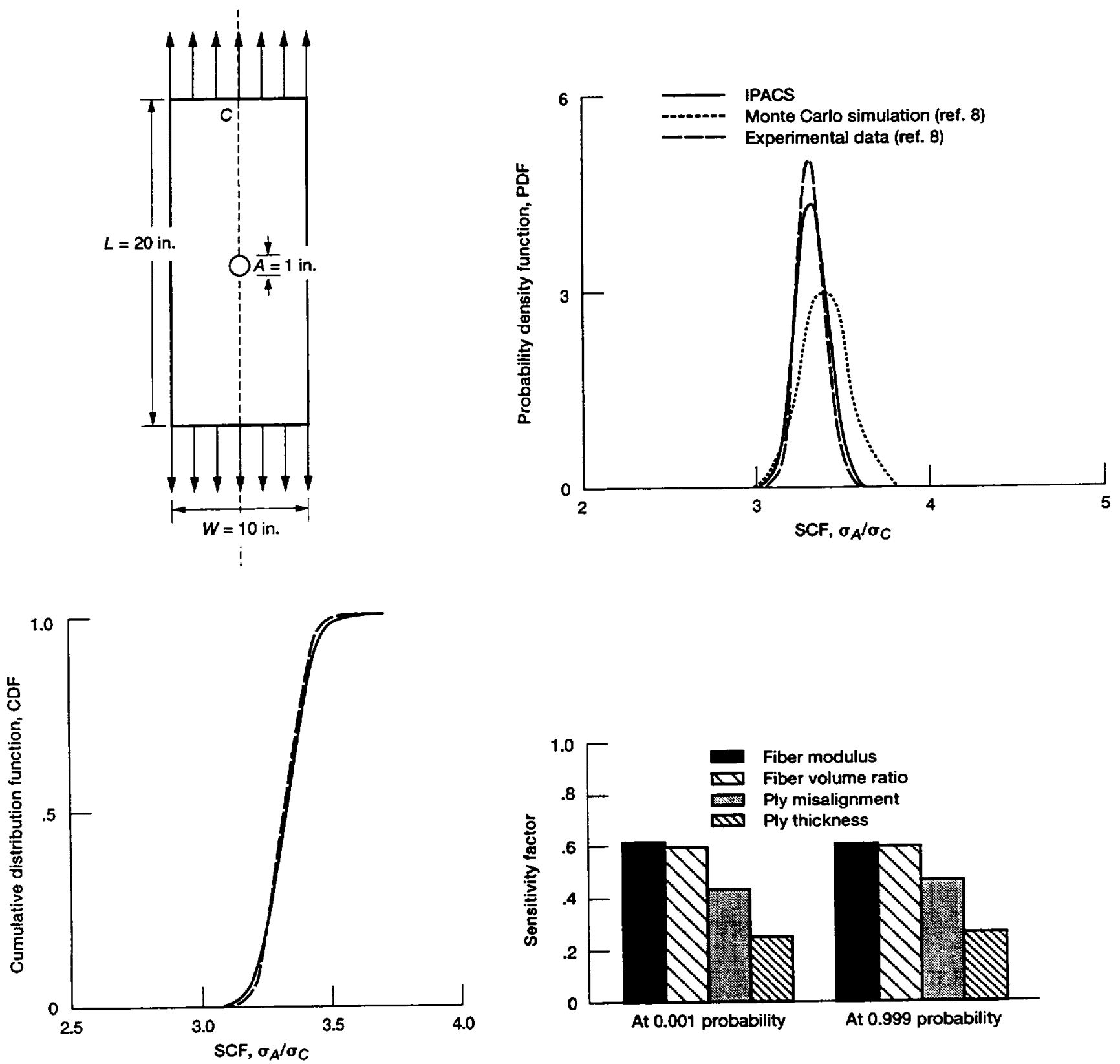

Figure 4.-Probabilistic stress concentration factor (SCF) for a $(0 / \pm 45 / 0 / \overline{90})$ s boron/epoxy laminate plate. Fiber and matrix properties with 2.5-percent scatter; thickness with 2.5 -percent scatter, and ply alignment with $2.25^{\circ}$ scatter. 


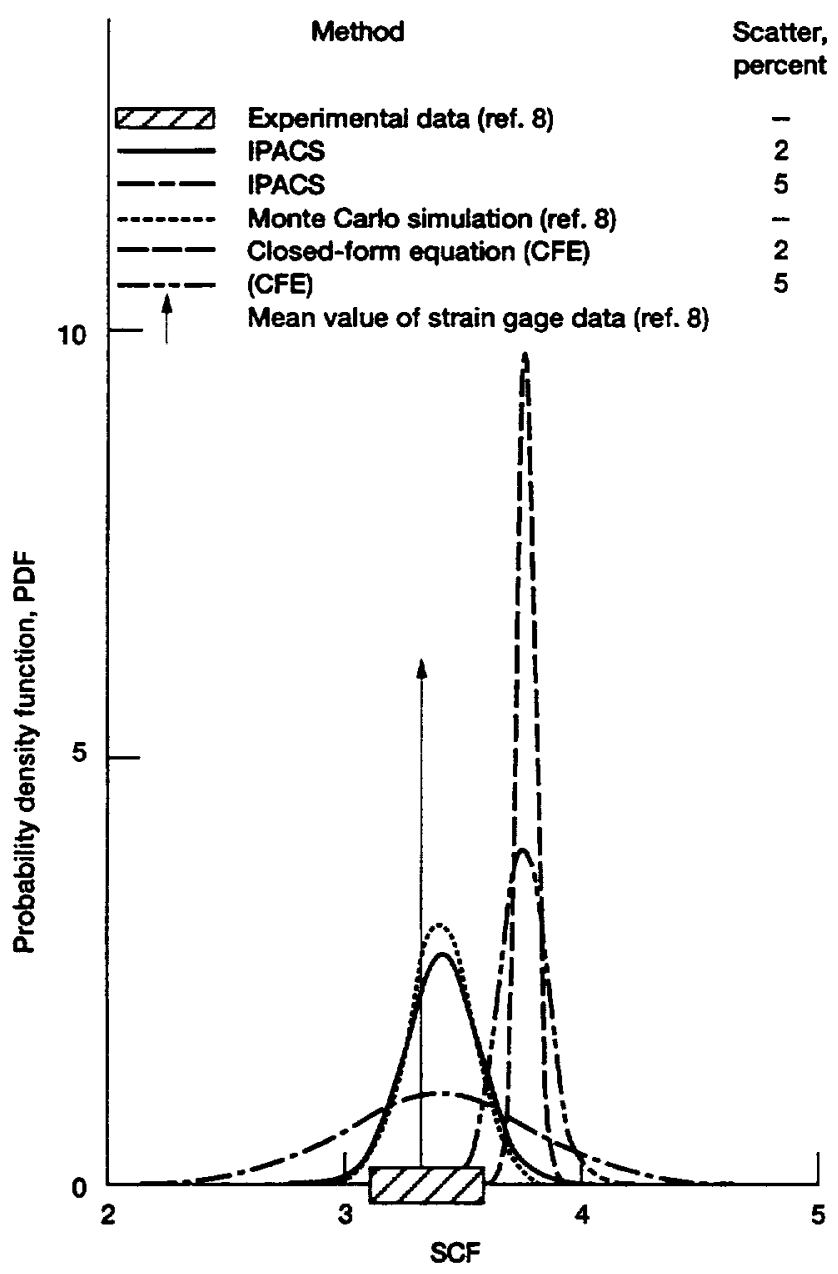

Figure 5.-Probabilistic stress concentration factor (SCF) for a $(0 / \pm 45 / 0 / \overline{90})$ s boron/epoxy laminate plate. 

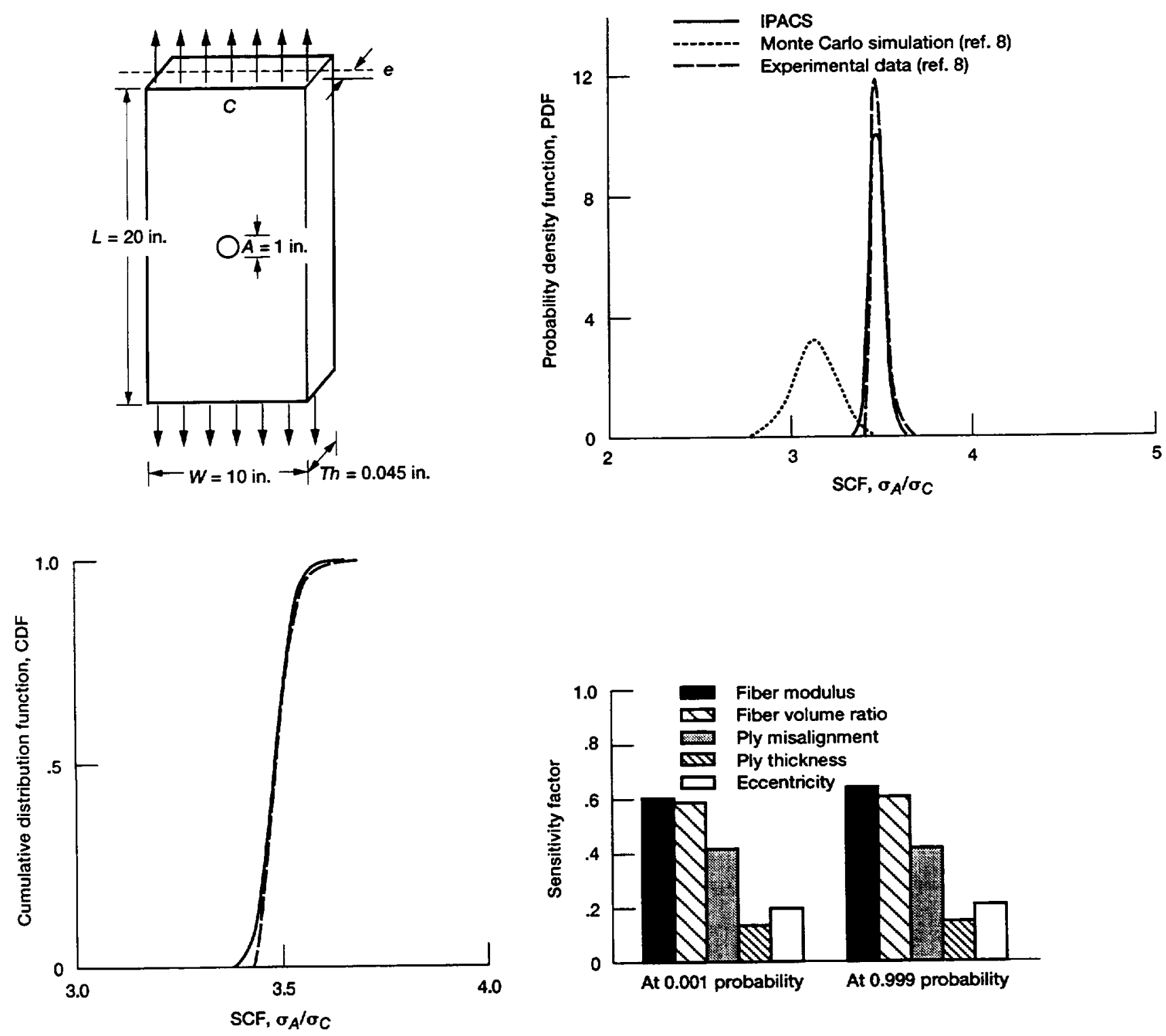

Figure 6.-Probabilistic stress concentration factor (SCF) for a $(0 / \pm 45 / 0 / \overline{90})$ s glass/epoxy laminate plate. Fiber and matrix properties with 1 -percent scatter, thickness with 1-percent scatter; ply alignment with $0.9^{\circ}$ scatter, mean of eccentricity, e, 3 percent of $T h$; and coefficient of variation of $e, 2$ percent of mean. 

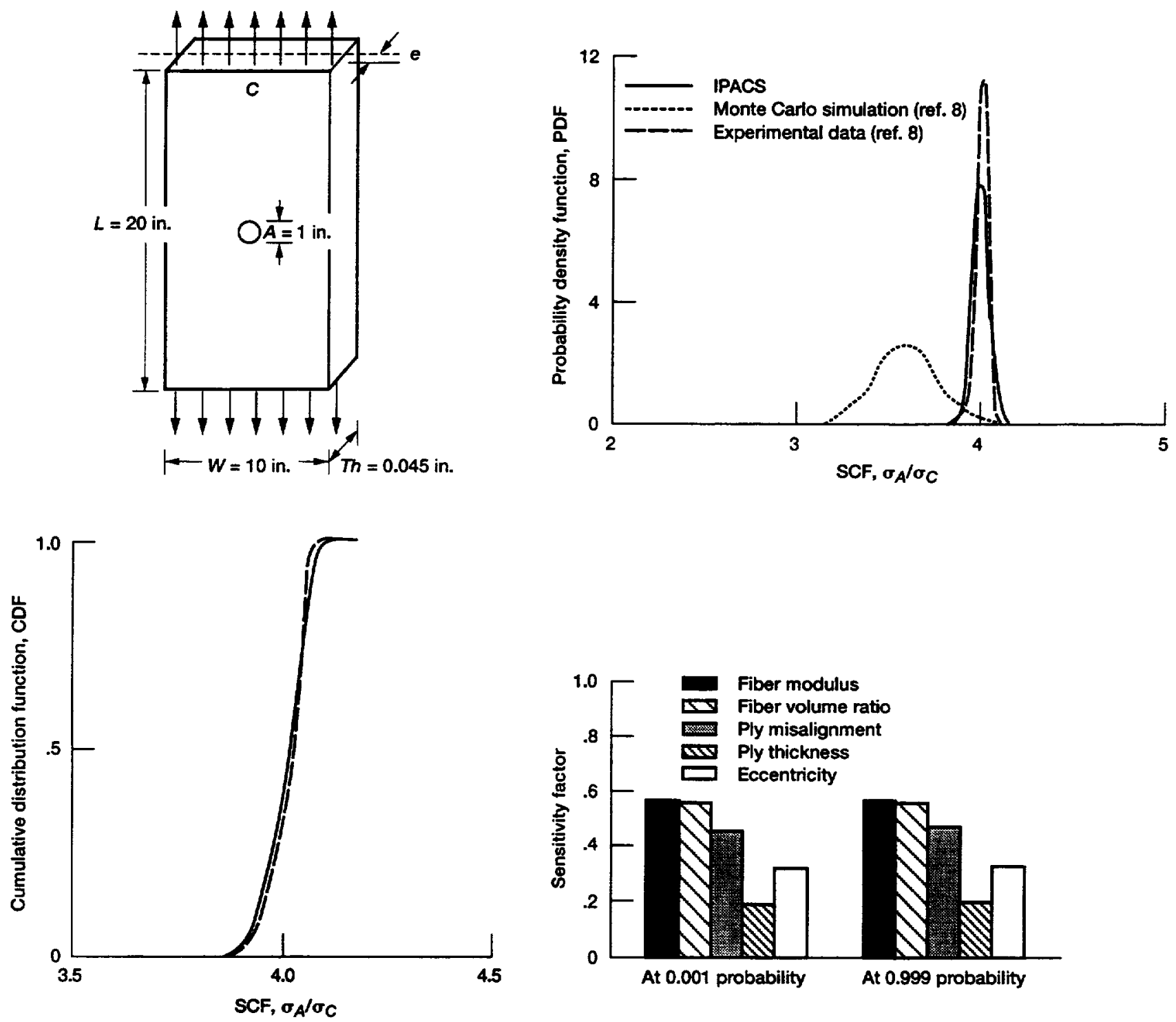

Figure 7.-Probabilistic stress concentration factor (SCF) for a $(0 / \pm 45 / 0 / \overline{90})$ s graphite/epoxy laminate plate. Fiber and matrix properties with 1-percent scatter; thickness with 1 -percent scatter, ply alignment with $0.9^{\circ}$ scatter, mean of $e, 7$ percent of $T h$; and coefficient of variation of $e, 2$ percent of mean. 

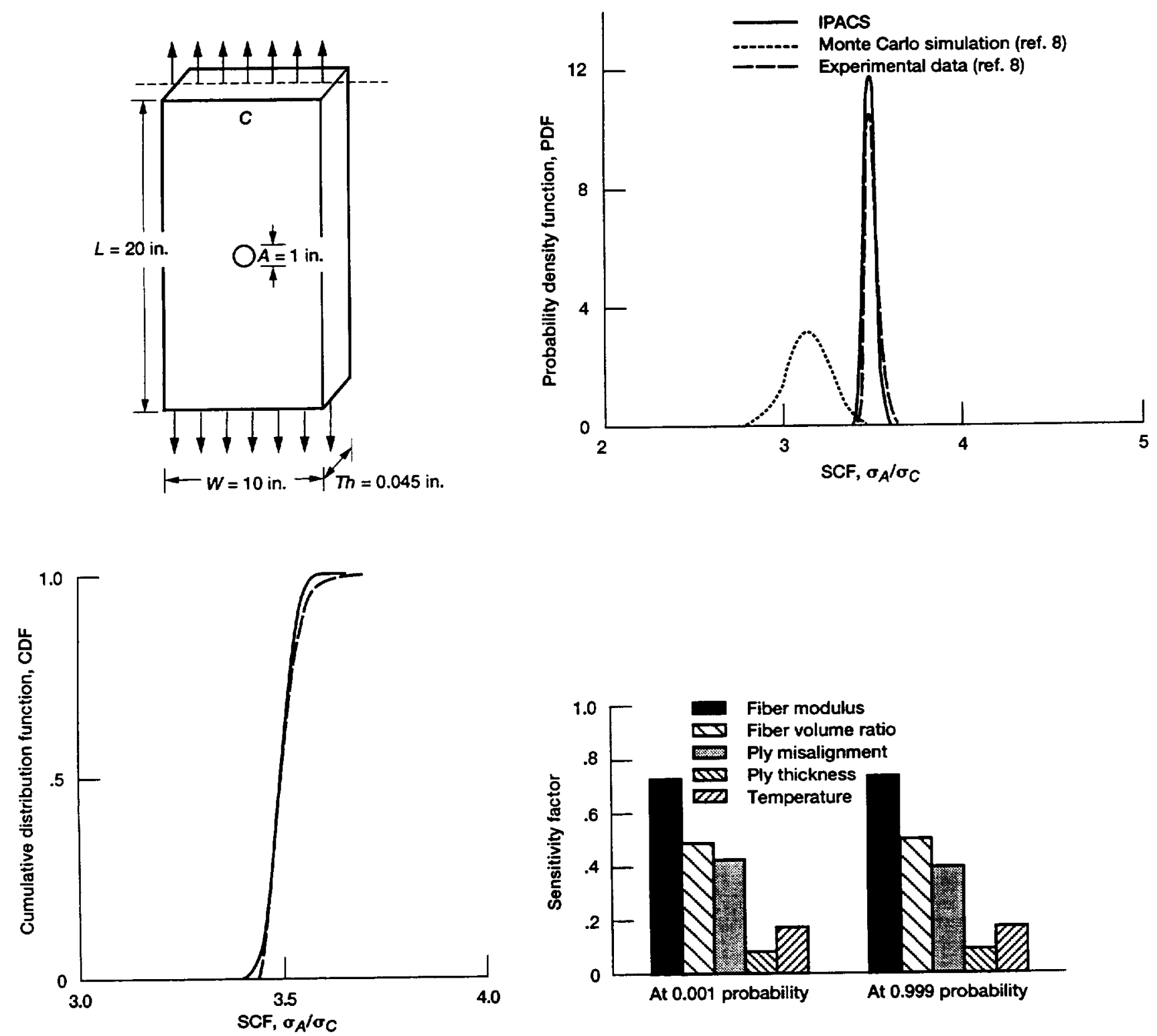

Figure 8. - Probabilistic stress concentration factor (SCF) for a $(0 / \pm 45 / 0 / \overline{90})$ s glass/epoxy laminate plate (initial stress effect). Fiber and matrix properties with 1-percent scatter; thickness with 1-percent scatter; ply alignment with $0.9^{\circ}$ scatter, and reference temperature, $70^{\circ} \mathrm{F}$, and cure temperature, $150^{\circ} \mathrm{F}$, with $5^{\circ} \mathrm{F}$ scatter. 

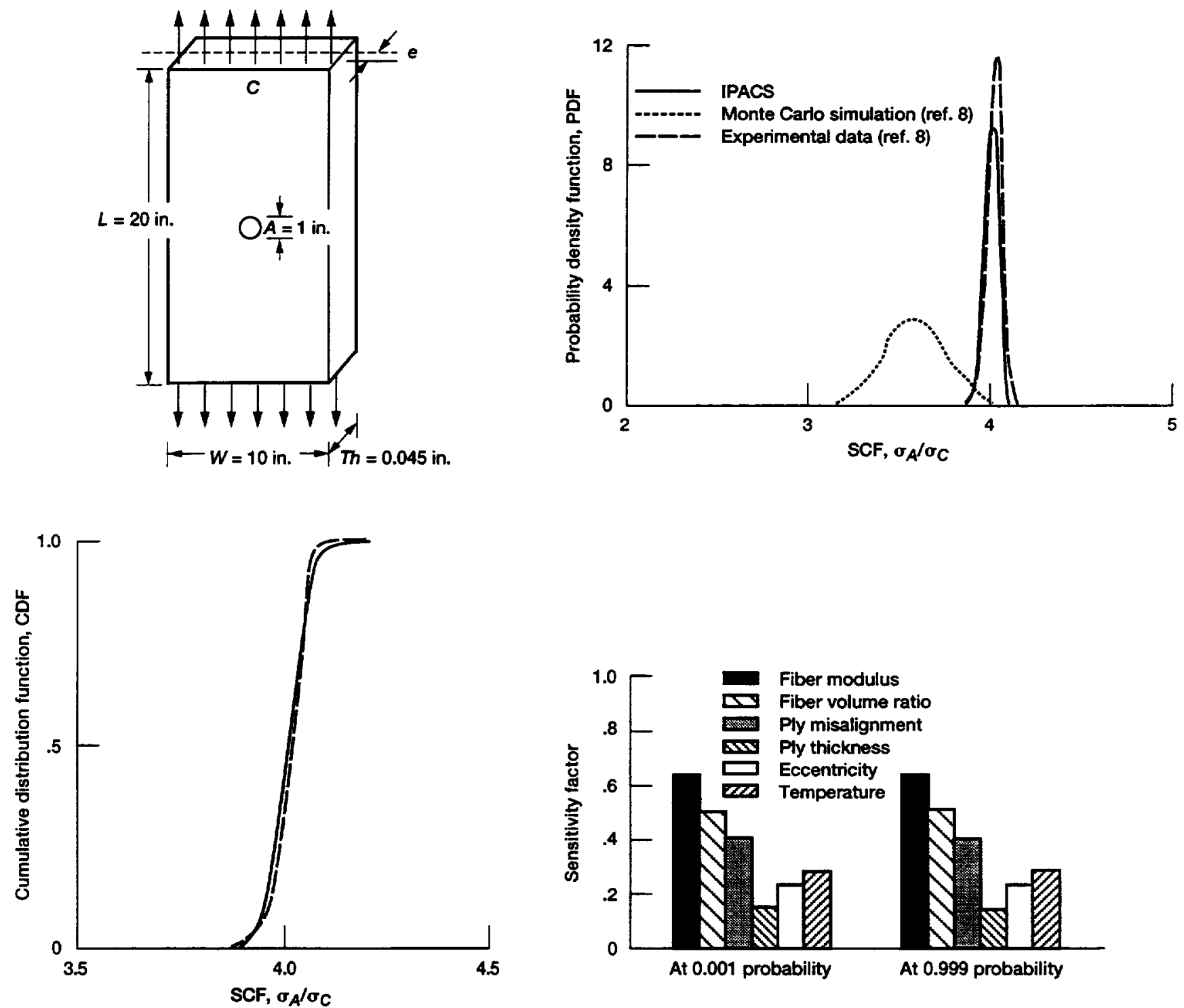

Figure 9.-Probabilistic stress concentration factor (SCF) for a $(0 / \pm 45 / 0 / \overline{90}) s$ graphite/epoxy laminate plate (initial stress effect). Fiber and matrix properties with 1-percent scatter; thickness with 1-percent scatter; ply alignment with $0.9^{\circ}$ scatter, reference temperature, $70{ }^{\circ} \mathrm{F}$, and cure temperature, $150^{\circ} \mathrm{F}$, with $5^{\circ} \mathrm{F}$ scatter, mean of e, 3.5 percent of $T h$; and coefficient of variation of e, 2 percent of mean. 

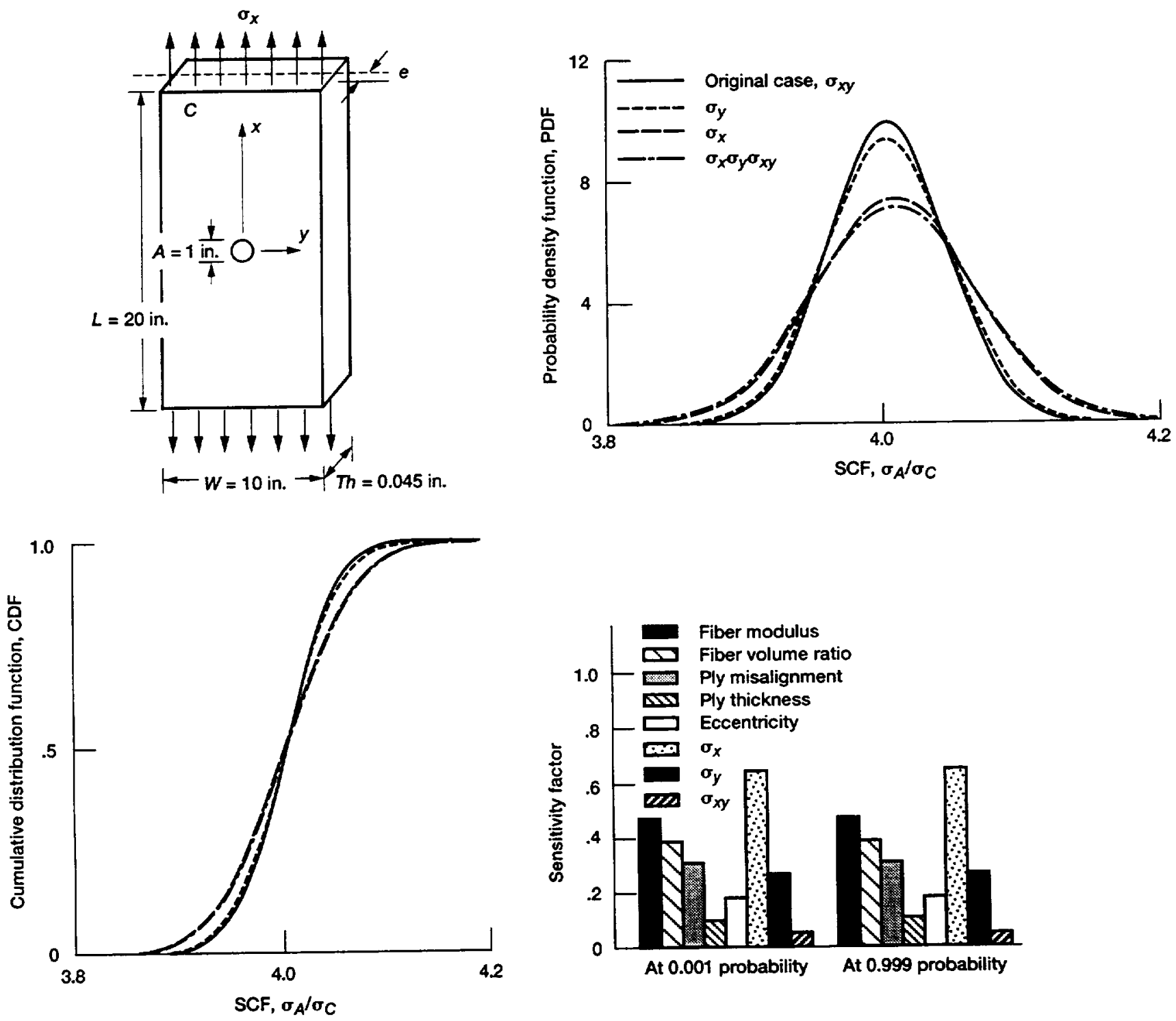

Figure 10.-Probabilistic stress concentration factor (SCF) for a $(0 / \pm 45 / 0 / \overline{90})$ s graphite/epoxy laminate plate (combined stresses effect). Fiber and matrix properties with 1-percent scatter, thickness with 1-percent scatter, ply alignment with $0.9^{\circ}$ scatter, reference temperature, $70^{\circ} \mathrm{F}$, and cure temperature, $350^{\circ} \mathrm{F}$, with $10^{\circ} \mathrm{F}$ scatter, e, 3.5 percent of $\mathrm{Th}$, with 2-percent scatter, and $\sigma_{x}, \sigma_{y}$, and $\sigma_{x y}$ with 1-percent scatter. 
Public reporting burden for this collection of Intormation is estimated to average 1 hour per response, including the time for reviewing instructions, searching existing data sources. gathering and maintaining the data needed, and corrpleting and reviewing the collection of intormation. Send comments regarding this burden estimate of any other aspect of this collection of information, including suggestions for reducing this burden, to Washington Headquarters Services, Directorate for Intormation Operations and Reports, 1215 Jetierson Davis Highway, Suite 1204, Arlington, VA 22202-4302, and to the Ottice of Management and Budget, Papenwork Reduction Project (0704-0188). Washington, DC 20503.

\begin{tabular}{|l|l|r|} 
1. AGENCY USE ONLY (Leave blank) & $\begin{array}{c}\text { 2. REPOAT DATE } \\
\text { December } 1994\end{array}$ & $\begin{array}{r}\text { 3. REPORT TYPE AND DATES COVERED } \\
\text { Technical Memorandum }\end{array}$
\end{tabular}

4. TITLE AND SUBTITLE

5. FUNDING NUMBERS

Probabilistic Simulation of Stress Concentration in Composite Laminates

6. AUTHOR(S)

C.C. Chamis, P.L.N. Murthy, and D.G. Liaw

WU-510-02-12

7. PERFORMNG ORGANIZATION NAME(S) AND ADDRESS(ES)

8. PERFORMING ORGANIZATION REPORT NUMBER

National Aeronautics and Space Administration

Lewis Research Center

Cleveland, Ohio 44135-3191

E-9077

9. SPONSORINGNONITORING AGENCY NAME(S) AND ADDRESS(ES)

10. SPONSORINGMONITORING AGENCY REPORT NUMBER

National Aeronautics and Space Administration

Washington, D.C. 20546-0001

NASA TM-106712

11. SUPPLEMENTARY NOTES

Prepared for the 34th Structures, Structural Dynamics, and Materials (SDM) Conference cosponsored by AIAA, ASME, ASCE, AHS, and ASC, La Jolla, California, April 19-22, 1993. C.C. Chamis and P.L.N. Murthy, NASA Lewis Research Center; D.G. Liaw, Sverdrup Technology, Inc., Lewis Research Center Group, Brook Park, Ohio 44142 (work funded by NASA Contract NAS3-25266). Responsible person, C.C. Chamis, organization code 5200, (216) 433-3252.

12a. DISTRIBUTIONAVAILABILTYY STATEMENT

12b. DISTAIBUTION CODE

Unclassified - Unlimited

Subject Category 39

13. ABSTRACT (Maximum 200 words)

A computational methodology is described to probabilistically simulate the stress concentration factors (SCF's) in composite laminates. This new approach consists of coupling probabilistic composite mechanics with probabilistic finite element structural analysis. The composite mechanics is used to probabilistically describe all the uncerainties inherent in composite material properties, whereas the finite element is used to probabilistically describe the uncertainties associated with methods to experimentally evaluate SCF's, such as loads, geometry, and supports. The effectiveness of the methodology is demonstrated by using it to simulate the SCF's in three different composite laminates. Simulated results match experimental data for probability density and for cumulative distribution functions. The sensitivity factors indicate that the SCF's are influenced by local stiffness variables, by load eccentricities, and by initial stress fields.

14. SUBJECT TERMS

Probabilistic mechanics; Probabilistic finite-element; Constituent materials; Fibers; Matrices; Probability distributions; Eccentricities; Thermal stress; Combined stresses; Sensitivities; Boron; Glass; Graphite; Epoxy

17. SECURITY CLASSIFICATION 1 18. SECURTY CLASSIFICATION OF REPORT OF THIS PAGE

Unclassified

Unclassified 19. SECURITY CLASSIFICATION
OF ABSTRACT Unclassified 


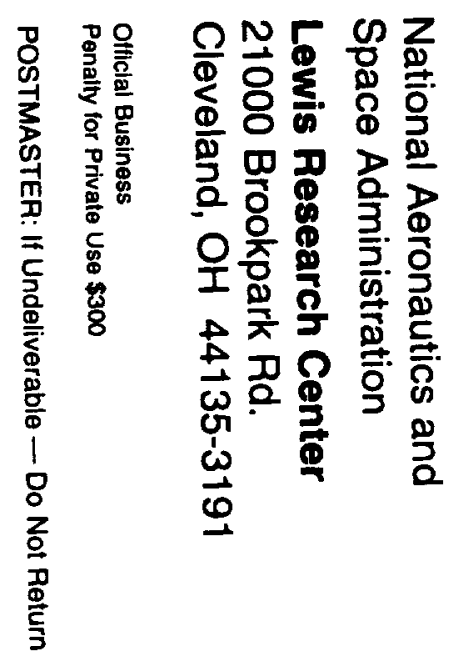


